Journal of Zhejiang University-SCIENCE A (Applied Physics \& Engineering)

ISSN 1673-565X (Print); ISSN 1862-1775 (Online)

www.zju.edu.cn/jzus; www.springerlink.com

E-mail: jzus@zju.edu.cn

\title{
Erratum:
}

\section{Erratum to: Effects of index angle on flow ripple of a tandem axial piston pump}

\author{
Bing XUं, Shao-gan YE, Jun-hui ZHANG \\ (The State Key Laboratory of Fluid Power Transmission and Control, Zhejiang University, Hangzhou 310027, China) \\ †E-mail: bxu@zju.edu.cn
}

doi: 10.1631 jzus.A14e0309

Erratum to: J Zhejiang Univ-Sci A (Appl Phys \& Eng) 2015 16(5):404-417 doi:10.1631/jzus.A1400309

The original version of this article unfortunately contained two mistakes. In p.406 and p.408, the titles of Figs. 2 and 3 were missing, which are given below:

Fig. 2 Schematic diagram of the pump model (a) and single piston chamber model (b). $V_{\mathrm{p}}$ is the velocity of the piston (Fig. 2a is reprinted from (Ye et al., 2014), Copyright 2014, with permission from ASME).

Fig. 3 Test rig used to measure the flow ripple of axial piston pumps (Reprinted from (Ye et al., 2014), Copyright 2014, with permission from ASME).

The online version of the original article can be found at http://dx.doi.org/10.1631/jzus.A1400309

(C) Zhejiang University and Springer-Verlag Berlin Heidelberg 2015 